\title{
Risk assessment for preeclampsia in women with gestational diabetes mellitus
}

\author{
Chadakarn Phaloprakarn* and Siriwan \\ Tangjitgamol \\ Department of Obstetrics and Gynecology, Bangkok \\ Metropolitan Administration Medical College and \\ Vajira Hospital, Bangkok, Thailand
}

\begin{abstract}
Aim: To develop a clinical model to assess the risk of preeclampsia in women with gestational diabetes mellitus (GDM).

Methods: We studied clinical characteristics of 813 consecutive women who had GDM between January 2003 and February 2008 at our institution. The clinical features which were significantly associated with preeclampsia by multiple logistic regression analysis were integrated into a risk model. The diagnostic performance of this model was then evaluated from a receiver-operating characteristic $(\mathrm{ROC})$ curve analysis.

Results: A total of 78 women with GDM (9.6\%) developed preeclampsia. In a multivariable analysis, firsttrimester $\mathrm{BMI} \geq 27 \mathrm{~kg} / \mathrm{m}^{2}(\mathrm{P}<0.001)$, GDM diagnosed within 20 weeks of gestation $(P<0.001)$, and poor glycemic control $(P<0.001)$ were associated with preeclampsia. These three factors were incorporated into a risk-scoring model which ranged from 0 to 3 points. At the optimal cut-off score of $\geq 2$, the sensitivity, specificity, and area under the curve (AUC) for preeclampsia were high at $76.9 \%$ [95\% confidence interval (Cl) 69.0-85.2], 92.8\% (95\% Cl 85.9-98.1), and 0.849 (95\% Cl 0.792-0.905), respectively.

Conclusion: A model based on clinical data yielded predicted the development of preeclampsia in women with GDM.
\end{abstract}

Keywords: Clinical model; gestational diabetes mellitus (GDM); preeclampsia; risk assessment.

\footnotetext{
*Corresponding author:

Chadakarn Phaloprakarn, MD

Department of Obstetrics and Gynecology

Bangkok Metropolitan Administration Medical College and

Vajira Hospital

681 Samsen Road

Dusit District

Bangkok 10300

Thailand

Tel.: +66 22443414

Fax: +66 22437907

E-mail: chadakarn_pt@yahoo.com
}

\section{Introduction}

Preeclampsia is a common obstetric complication and is one of the leading causes of maternal and fetal mortality worldwide $[11,20]$. At present, the precise etiology of preeclampsia remains unknown $[19,20]$, thus limiting its prevention. Nevertheless, prevention of serious complications, such as seizure, coagulopathy, stroke, etc. could be accomplished by providing more intensive antenatal surveillance to women who are at high risk.

Data suggest that women with gestational diabetes mellitus (GDM) are at increased risk of preeclampsia [3, $8,21,23,24]$. Several authors [8, 23, 24] explained that carbohydrate intolerance or insulin resistance might play an etiological role in the development of the hypertensive disorder. Such explanation was supported by the findings of high glucose or insulin levels prior to the onset of hypertension in pregnancy $[12,13,15]$. In addition, some clinical features which are related to insulin resistance [10], such as obesity and degree of hyperglycemia, were independently associated with preeclampsia in women with GDM [21, 23, 24].

Taking into account that the global prevalence of GDM has continuously increased over the past decades [6, 7], this would certainly result in an increased number of pregnant women being at risk of diabetes-related complications including preeclampsia. Focusing on this global trend, identification of women with GDM who will later develop preeclampsia might improve the pregnancy outcome.

Although some studies [21, 23, 24] had used clinical data of the women with GDM to evaluate the risk for preeclampsia, no risk model was developed. We aimed to generate a clinical model to assess the risk of preeclampsia in this particular group of women and to determine the diagnostic performance of this model.

\section{Methods}

The study was conducted after approval of the Bangkok Metropolitan Administration Ethics Committee for Researches Involving Human Subjects. Eligibility criteria were consecutive pregnant women who had GDM between January 2003 and February 2008 and attended our antenatal clinic within the first trimester ( $\leq 14$ weeks). Exclusion criteria were individuals who had: multiple gestation, certain risk to develop preeclampsia (i.e., chronic hypertension, overt diabetes, renal or collagen vascular disease, or hyperthyroidism), smoking, and delivery in another hospital. 
All pregnant women in the study underwent glucose challenge test (GCT) by universal screening for GDM according to the departmental policy. Women without any risk factors were screened at 24-28 weeks of gestation. Those with the following characteristics were screened at an initial visit or as soon as feasible: age $\geq 35$ years, body mass index (BMI) $\geq 27 \mathrm{~kg} / \mathrm{m}^{2}$, any first-degree relatives with type-2 diabetes, personal history of GDM, prior delivery of a newborn weighing $\geq 4000 \mathrm{~g}$, history of any adverse obstetric events ( $\geq 2$ miscarriages, congenital malformation, or stillbirth), or glucosuria. If the first GCT revealed normal result, the test was repeated at 28-32 weeks. Individuals with abnormal GCT (glucose value $\geq 7.8 \mathrm{mmol} / \mathrm{L}$ or $\geq 140 \mathrm{mg} /$ $\mathrm{dL}$ ) would be scheduled for a diagnostic 100-g oral glucose tolerance test (OGTT). For a diagnosis of GDM in this study, we used the Carpenter and Coustan criteria [1]. All women who were diagnosed as having GDM were treated with diet modification with or without insulin. Insulin would be generally given to any woman whose fasting glucose from an OGTT was $\geq 5.8 \mathrm{mmol} / \mathrm{L}$ ( $\geq 105 \mathrm{mg} / \mathrm{dL}$ ), or a woman who could not maintain fasting or 2-h postprandial plasma glucose $<5.3 \mathrm{mmol} / \mathrm{L}$ ( $<95 \mathrm{mg} / \mathrm{dL})$ or $<6.7 \mathrm{mmol} / \mathrm{L}(<120 \mathrm{mg} / \mathrm{dL})$, respectively, after a 4-week period of diet control.

Data collected were: maternal age, parity, BMI at first visit, GCT and OGTT values, gestational age (GA) at GDM diagnosis, treatment modality, glycemic profiles after diet control and/or insulin treatment, and the presence or absence of preeclampsia. Maternal age was assigned in the whole number of years at the time of initial booking. BMI was calculated from weight and height, which were measured using the same scaling equipment at the antenatal clinic for all pregnant women. Individuals were diagnosed as having obesity if the first-trimester BMI was $\geq 27 \mathrm{~kg} / \mathrm{m}^{2}$ [9]. We defined poor glycemic control as $\geq 2$ separate occasions of fasting glucose $\geq 5.8 \mathrm{mmol} / \mathrm{L}(\geq 105 \mathrm{mg} / \mathrm{dL})$ and/or 2-h postprandial glucose $\geq 6.7 \mathrm{mmol} / \mathrm{L}(\geq 120 \mathrm{mg} / \mathrm{dL})$ after GDM treatment. Preeclampsia was diagnosed using the criteria of the International Society for the Study of Hypertension in Pregnancy [2].

Statistical analysis was performed with the SPSS software package version 11.5 (SPSS Inc., Chicago, IL, USA). The STATA 7.0 (Stata Corp., College Station, TX, USA) was additionally used to generate confidence intervals (Cls). Continuous variables were presented as mean and standard deviation (SD), and categorical variables as $\mathrm{N}(\%)$. The Student $t$-test was used to compare continuous variables, and $\chi^{2}$-test was used to compare categorical variables. $\mathrm{P}$-value $<0.05$ was considered statistically significant. The clinical characteristics which were significantly associated with preeclampsia by univariate analysis were entered into a multiple logistic regression; the goodness of fit was assessed by the Hosmer-Lemeshow test. The regression coefficients of significant variables were divided by the lowest value among them and were rounded to the nearest integer [18]. These figures were then summed up into a model to derive a risk score. The sensitivity, specificity, positive predictive value (PPV), and negative predictive value (NPV) with associated 95\% Cls for preeclampsia were calculated at each cut-off point. A receiver-operating characteristic $(\mathrm{ROC})$ curve was constructed and the area under the curve (AUC) was then calculated to determine the optimal cut-off score.

\section{Results}

A total of 813 women with GDM were included in the study. Of these, 92\% were Thai and the remaining $8 \%$ were other Southeast Asians. Seventy-eight women (9.6\%) developed preeclampsia; 15/78 (19.2\%) had a severe disease. Characteristic features of individuals in the preeclamptic and non-preeclamptic groups are shown in Table 1. Women from both groups had no significant differences in mean age, rates of nullipara and insulin use. In comparison to those without preeclampsia, women who experienced preeclampsia had significantly higher rates of obesity and poor glycemic control, higher mean GCT and OGTT values, and earlier GA at GDM diagnosis.

The independent risk factors for preeclampsia development in women with GDM are shown in Table 2. Firsttrimester $\mathrm{BMI} \geq 27 \mathrm{~kg} / \mathrm{m}^{2}$, GDM diagnosed within 20 weeks of gestation, and poor glycemic control were identified as significant factors from a multivariable

Table 1 Characteristics of gestational diabetes mellitus women who developed and did not develop preeclampsia $(n=813)$.

\begin{tabular}{lllr}
\hline & $\begin{array}{l}\text { Preeclampsia } \\
(\mathrm{n}=78)\end{array}$ & $\begin{array}{l}\text { No preeclampsia } \\
(\mathrm{n}=735)\end{array}$ & P-value \\
\hline Age (years), mean (SD) & $32.2(5.2)$ & $31.2(5.3)$ & 0.26 \\
Nullipara, $\mathrm{n}(\%)$ & $28(35.9)$ & $297(40.4)$ & 0.44 \\
First-trimester BMI $\geq 27 \mathrm{~kg} / \mathrm{m}^{2}, \mathrm{n}(\%)$ & $65(83.3)$ & $182(24.8)$ & $<0.001$ \\
GCT value (mmol/L), mean (SD) & $10.6(3.7)$ & $9.8(2.1)$ & $<0.001$ \\
OGTT result (mmol/L), mean (SD) & & & $<.1(1.2)$ \\
$\quad$ Fasting value & $6.6(2.6)$ & $10.9(1.9)$ & $<0.001$ \\
1 h value & $12.7(4.0)$ & $9.7(2.3)$ & $<0.001$ \\
2 h value & $11.4(4.7)$ & $8.0(3.3)$ & $<0.001$ \\
3 h value & $9.6(4.0)$ & $26.7(5.9)$ & $<0.001$ \\
GA at GDM diagnosis (weeks), mean (SD) & $18.2(7.0)$ & $243(33.1)$ & 0.06 \\
Insulin treatment, $\mathrm{n}(\%)$ & $34(43.6)$ & $70(9.5)$ & $<0.001$ \\
Poor glycemic control ${ }^{*}, \mathrm{n}(\%)$ & $48(61.5)$ & & $<$ \\
\hline
\end{tabular}

${ }^{*}$ Defined as $\geq$ two occasions of fasting glucose $\geq 5.8 \mathrm{mmol} / \mathrm{L}$ and/or 2 -h postprandial glucose $\geq 6.7 \mathrm{mmol} / \mathrm{L}$ after diet and/or insulin treatment.

$\mathrm{BMI}=$ body mass index, $\mathrm{GA}=$ gestational age, $\mathrm{GCT}=$ glucose challenge test, $\mathrm{GDM}=$ gestational diabetes mellitus, $\mathrm{OGTT}=$ oral glucose tolerance test, $\mathrm{SD}=$ standard deviation. 
Table 2 Odds ratios of risk factors for preeclampsia in gestational diabetes mellitus women.

\begin{tabular}{lcc}
\hline & Adjusted odds ratio* & $95 \% \mathrm{Cl}$ \\
\hline First-trimester BMI $\geq 27 \mathrm{~kg} / \mathrm{m}^{2}$ & 10.44 & $5.25-20.79$ \\
GCT value $\geq 10.0 \mathrm{mmol} / \mathrm{L}$ & 1.48 & $0.74-2.95$ \\
Fasting OGTT value $\geq 5.3 \mathrm{mmol} / \mathrm{L}$ & 0.90 & $0.44-1.82$ \\
$1 \mathrm{~h}$ OGTT value $\geq 10.0 \mathrm{mmol} / \mathrm{L}$ & 1.29 & $0.57-2.92$ \\
$2 \mathrm{~h}$ OGTT value $\geq 8.6 \mathrm{mmol} / \mathrm{L}$ & 0.65 & $0.34-1.24$ \\
$3 \mathrm{~h}$ OGTT value $\geq 7.8 \mathrm{mmol} / \mathrm{L}$ & 1.68 & $0.86-3.25$ \\
GA at GDM diagnosis $\leq 20$ weeks & 8.00 & $4.30-14.91$ \\
Poor glycemic control & 8.40 & $4.57-15.42$ \\
\hline
\end{tabular}

${ }^{*}$ Adjusted for the other variables in the table.

$\mathrm{BMI}=$ body mass index, $\mathrm{Cl}=$ confidence interval, $\mathrm{GA}=$ gestational age, GCT=glucose challenge test, GDM=gestational diabetes mellitus, OGTT = oral glucose tolerance test.

analysis. The Hosmer-Lemeshow test did not reject the goodness of fit of the model $(P=0.792)$.

Table 3 shows the risk score points for preeclampsia. The coefficient values of these variables were 2.080, 2.128, and 2.346. These figures were divided by 2.080 before being rounded to the nearest integer. This resulted in a final score of one for each variable. The total risk score of each woman would range from 0 to 3 accordingly. The overall AUC of the clinical model was 0.911 (95\% Cl: 0.877-0.946). The cut-off point of $\geq 2$ was optimal (Figure 1), yielding a sensitivity of $76.9 \%$ and specificity of $92.8 \%$ (Table 4). By using this cut-off level, 113/ 813 women with GDM (13.9\%) would be considered at high risk of preeclampsia. Among these 113 at-risk women, 60 (53.1\%) actually had subsequent preeclampsia; 49 developed mild degree of the disorder while 11 were determined as severe. The rate of women with GDM who developed preeclampsia appeared to directly associate with the risk scores; the incidences of preeclampsia increased as the risk score was higher (Table 5).

\section{Discussion}

The prevalence of preeclampsia in our GDM population was $9.6 \%$ which was in the range of $9-10 \%$ in other ethnic groups [21, 23, 24]. Our results showed that maternal obesity, early GDM diagnosis, and poor glycemic control were the three independent factors contributing to preeclampsia. These findings were consistent with previous studies [21, 23, 24] which demonstrated that obesity and degree of hyperglycemia were indepen-

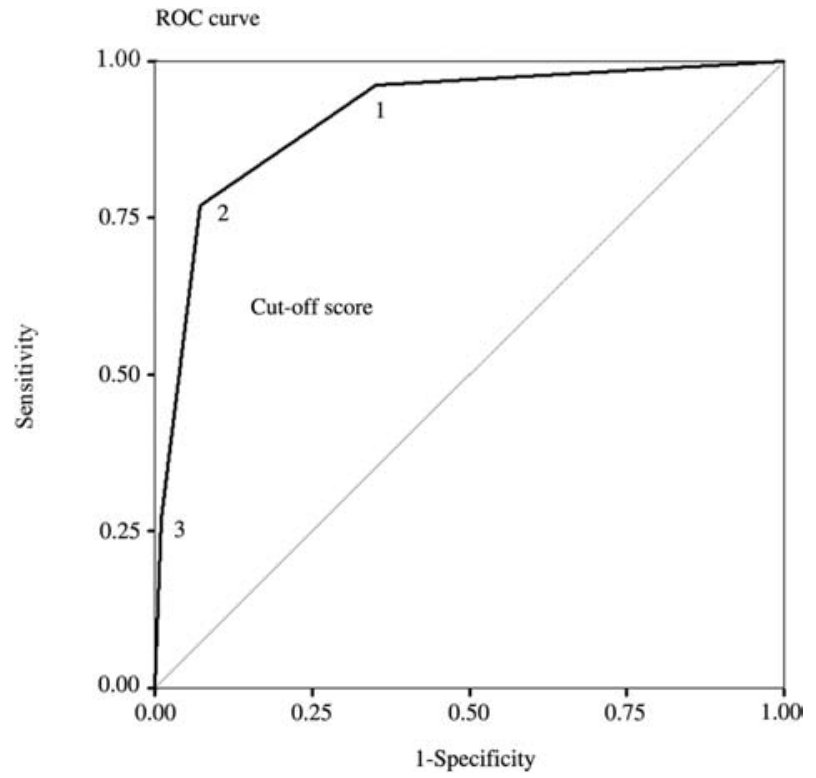

Figure 1 A receiver-operating characteristic curve of the risk score for preeclampsia in gestational diabetes mellitus women. Each number on the line represents each cut-off score.

dently associated with preeclampsia. Few studies [12, $13,15]$ reported that the association of such two features with preeclampsia might be related to insulin resistance. Nevertheless, this was not corroborated from one recent study [14] which found no differences of insulin resistance between women who developed or did not develop preeclampsia by a direct measurement of insulin

Table 3 Risk score based on clinical characteristics of gestational diabetes mellitus women for the development of preeclampsia.

\begin{tabular}{lll}
\hline Clinical characteristic & Coefficient $^{\text {Point* }}$ \\
\hline First-trimester BMI $\geq 27 \mathrm{~kg} / \mathrm{m}^{2}$ & 2.346 \\
GA at GDM diagnosis $\leq 20$ weeks & 2.080 \\
Poor glycemic control & 2.128 \\
Maximum score & - & 1 \\
\hline
\end{tabular}

*Point was assigned to each variable based on its regression coefficient value. Each coefficient was divided by 2.080 (the lowest coefficient value, corresponding to GA at GDM diagnosis $\leq 20$ weeks), and rounded to the nearest integer.

$\mathrm{BMI}=$ body mass index, $\mathrm{GA}=$ gestational age, $\mathrm{GDM}=$ gestational diabetes mellitus. 
Table 4 Diagnostic performance of each cut-off score for preeclampsia in gestational diabetes mellitus women.

\begin{tabular}{llllll}
\hline Cut-off point & Sensitivity $(95 \% \mathrm{Cl})$ & Specificity $(95 \% \mathrm{Cl})$ & $\mathrm{PPV}(95 \% \mathrm{Cl})$ & $\mathrm{NPV}(95 \% \mathrm{Cl})$ & $\mathrm{AUC}(95 \% \mathrm{Cl})$ \\
\hline 1 & $96.2(91.9-98.8)$ & $64.8(57.3-72.2)$ & $22.5(15.1-30.0)$ & $99.4(97.7-99.8)$ & $0.805(0.766-0.843)$ \\
2 & $76.9(69.0-85.2)$ & $92.8(85.9-98.1)$ & $53.1(46.4-60.5)$ & $97.4(95.0-98.7)$ & $0.849(0.792-0.905)$ \\
3 & $26.9(19.1-32.4)$ & $99.0(97.3-99.9)$ & $75.0(68.4-82.2)$ & $92.7(90.1-95.1)$ & $0.630(0.555-0.705)$ \\
\hline
\end{tabular}

$\mathrm{AUC}=$ area under the curve, $\mathrm{Cl}=$ confidence interval, $\mathrm{NPV}=$ negative predictive value, $\mathrm{PPV}=$ positive predictive value.

Table 5 Incidence rates of preeclampsia in various groups of gestational diabetes mellitus women categorized by their risk score $(n=813)$.

\begin{tabular}{llllr}
\hline Score & Number of women & \multicolumn{2}{c}{ Number of preeclampsia (\%) } \\
\cline { 3 - 5 } & & Mild degree & Severe degree & Total cases \\
\hline 0 & 479 & $3(0.6)$ & 0 & $3(0.6)$ \\
1 & 221 & $11(5.0)$ & $4(1.8)$ & $15(6.8)$ \\
2 & 85 & $33(38.8)$ & $6(7.1)$ & $39(45.9)$ \\
3 & 28 & $16(57.1)$ & $5(17.9)$ & $21(75.0)$ \\
\hline
\end{tabular}

resistance indices in GDM women. Aside from the mechanism of insulin resistance, other authors [5, 17] postulated that obesity might trigger the onset of preeclampsia via an inflammatory-mediated pathway. Levels of inflammatory parameters were substantially elevated while both endothelial-dependent and -independent vasodilatory responses were significantly reduced in obese pregnant women as compared to lean patients [17]. Likewise, in vivo evidence suggested that hyperglycemic condition could promote the formation of sugar-derived substances called advanced glycation end products (AGEs) $[4,25]$ which could, in turn, lead to endothelial dysfunction and arterial stiffening resulting in hypertension [16, 22]. Moreover, the deleterious effects of AGEs were driven by the duration and degree of hyperglycemia [16]. This may be the explanation for our findings of increased rate of preeclampsia in women who had early-onset GDM and poor glycemic control.

In this study, we integrated the significant characteristics of women with GDM into a risk model of preeclampsia. To improve the test's accuracy, we excluded several underlying diseases which may relate to preeclampsia and used first-trimester BMI instead of pregravid BMI to prevent a recall bias. In clinical application, our risk model which includes only variables obtained from basic physical examination and blood glucose testing would be practical and cost effective due to their availability and low cost. With the high AUC of the model, our algorithm could discriminate high versus low-risk women with GDM for preeclampsia. A risk score of 3 suggested that an individual has a high probability of $75.0 \%$ to develop preeclampsia (21/28 women), while a score of 0 indicated a low probability of only $0.6 \%$ (3/479 women).

In our clinical model, we did not speculate on the definition of poor glycemic control to any specific GA because the onset of GDM in each individual may vary from early to late pregnancy. Furthermore, the levels of plasma glucose could fluctuate throughout pregnancy depending on the continuity of measurement or intensity of treatment. In clinical practice, we suggest that the model could be used periodically when the fasting and postprandial plasma glucose levels are monitored. When poor glycemic control is encountered, its associated risk score would then evaluate the probability of preeclampsia.

The insulin use in our study was $34.1 \%(277 / 813$ women), which depended upon fasting hyperglycemia from the OGTT, or levels of glycemic control with diet modification. The rate of insulin use in the preeclamptic was similar to that in the non-preeclamptic women, approximately $44 \%$ compared to $33 \%$ despite the different rates of poor glycemic control $(62 \%$ compared to $10 \%$, respectively). Although we had a definite guideline for insulin use in our institution, the actual clinical use may vary according to many factors, such as lifestyle and compliance to dietary control, GA, and preference of the women/obstetricians/endocrinologists to initiate insulin therapy. This finding may actually result in the higher rate of preeclampsia in the poorly controlled compared to the well controlled groups, approximately $41 \%$ (48/118 women) compared to only $4 \%$ (30/695 women), respectively (data not shown). The link of well controlled GDM with a lower rate of preeclampsia in our study was in agreement with the results from previous studies [21, 24], which showed that achieving the desired level of glycemic control was associated with lower incidence of preeclampsia. Thus, stringent control of plasma glucose during pregnancy may be one preventive measure to reduce preeclampsia in GDM women.

As we found that first-trimester BMI $\geq 27 \mathrm{~kg} / \mathrm{m}^{2}$ was one important predisposing factor for preeclampsia in women with GDM, an appropriate diet plan and education for obese pregnant women might be useful. To be optimistic, any obese woman should attend a weight 
reduction program or be encouraged to achieve an ideal body weight before conception.

Because women who turn out to have severe preeclampsia are in greater danger than those who remain mild preeclamptic, one may question if this risk model would still predict severe preeclampsia. At the cut-off score of $\geq 2$, the sensitivity and specificity for severe preeclampsia were $73.3 \%$ and $87.2 \%$ respectively, which were slightly lower than the performances (i.e., $76.9 \%$ sensitivity and $92.8 \%$ specificity) to detect any type of preeclampsia. Nevertheless, we could not make any definite conclusion regarding the role of the model in risk assessment of severe preeclampsia since our study had a small number of women $(n=15)$ who experienced such clinical manifestation. Further studies with larger samples are needed to examine this subject.

By the good diagnostic performance of our risk model, we suggest that the caregivers should be alert and closely monitor individuals who have a risk score of $\geq 2$. Aside from this, our model might be useful in selecting women for further studies on intervention or effective prophylactic means to prevent preeclampsia. Since our data were limited to a homogeneous population, different results might occur in other settings with different populations.

\section{References}

[1] American Diabetes Association. Gestational diabetes mellitus. Diabetes Care. 2004;27(Suppl 1):S88-90.

[2] Brown MA, Lindheimer MD, de Swiet M, Van Assche A, Moutquin JM. The classification and diagnosis of the hypertensive disorders of pregnancy: statement from the International Society for the Study of Hypertension in Pregnancy (ISSHP). Hypertens Pregnancy. 2001;20:IX-XIV.

[3] Bryson CL, loannou GN, Rulyak SJ, Critchlow C. Association between gestational diabetes and pregnancy-induced hypertension. Am J Epidemiol. 2003;158:1148-53.

[4] Bucala R, Tracey KJ, Cerami A. Advanced glycosylation products quench nitric oxide and mediate defective endothelium-dependent vasodilatation in experimental diabetes. J Clin Invest. 1991;87:432-8.

[5] Carpenter MW. Gestational diabetes, pregnancy hypertension, and late vascular disease. Diabetes Care. 2007;30 (Suppl. 2):S246-50.

[6] Dabelea D, Snell-Bergeon JK, Hartsfield CL, Bischoff KJ, Hamman RF, McDuffie RS. Increasing prevalence of gestational diabetes mellitus (GDM) over time and by birth cohort: Kaiser Permanente of Colorado GDM Screening Program. Diabetes Care. 2005;28:579-84.

[7] Ferrara A, Kahn HS, Quesenberry CP, Riley C, Hedderson $\mathrm{MM}$. An increase in the incidence of gestational diabetes mellitus: Northern California, 1991-2000. Obstet Gynecol. 2004;103:526-33.

[8] Innes KE, Wimsatt JH, McDuffie R. Relative glucose tolerance and subsequent development of hypertension in pregnancy. Obstet Gynecol. 2001;97:905-10.

[9] Jiménez-Moleón JJ, Bueno-Cavanillas A, Luna-del-Castillo JD, Lardelli-Claret P, García-Martín M, Gálvez-Vargas R.
Predictive value of a screen for gestational diabetes mellitus: influence of associated risk factors. Acta Obstet Gynecol Scand. 2000;79:991-8.

[10] Kaaja R, Laivuori H, Laakso M, Tikkanen MJ, Ylikorkala O. Evidence of a state of increased insulin resistance in preeclampsia. Metabolism. 1999;48:892-6.

[11] Khan KS, Wojdyla D, Say L, Gülmezoglu AM, Van Look PF. WHO analysis of causes of maternal death: a systematic review. Lancet. 2006;367:1066-74.

[12] Lorentzen B, Birkeland KI, Endresen MJ, Henriksen T. Glucose intolerance in women with preeclampsia. Acta Obstet Gynecol Scand. 1998;77:22-7.

[13] Martinez Abundis E, Gonzalez Ortiz M, Quiñones Galvan A, Ferrannini $\mathrm{E}$. Hyperinsulinemia in glucose-tolerant women with preeclampsia. A controlled study. Am J Hypertens. 1996;9:610-4.

[14] Montoro MN, Kjos SL, Chandler M, Peters RK, Xiang AH, Buchanan TA. Insulin resistance and preeclampsia in gestational diabetes mellitus. Diabetes Care. 2005;28:19952000.

[15] Nisell H, Erikssen C, Persson B, Carlström K. Is carbohydrate metabolism altered among women who have undergone a preeclamptic pregnancy? Gynecol Obstet Invest. 1999;48:241-6.

[16] Peppa M, Uribarri J, Vlassara H. Glucose, advanced glycation end products, and diabetes complications: what is new and what works. Clinical Diabetes. 2003;21:186-7.

[17] Ramsay JE, Ferrell WR, Crawford L, Wallace AM, Greer IA Sattar N. Maternal obesity is associated with dysregulation of metabolic, vascular, and inflammatory pathways. J Clin Endocrinol Metab. 2002;87:4231-7.

[18] Rassi A Jr, Rassi A, Little WC, Xavier SS, Rassi SG, Rassi $A G$, et al. Development and validation of a risk score for predicting death in Chagas' heart disease. N Engl J Med. 2006;355:799-808.

[19] Roberts JM, Cooper DW. Pathogenesis and genetics of pre-eclampsia. Lancet. 2001;357:53-6.

[20] Sibai B, Dekker G, Kupferminc M. Pre-eclampsia. Lancet. 2005;365:785-99.

[21] Sun Y, Yang H, Sun WJ. Risk factors for pre-eclampsia in pregnant Chinese women with abnormal glucose metabolism. Int J Gynaecol Obstet. 2008;101:74-6.

[22] Yamagishi S, Nakamura K, Imaizumi T. Advanced glycation end products (AGEs) and diabetic vascular complications. Curr Diabetes Rev. 2005;1:93-106.

[23] Yogev Y, Langer O, Brustman L, Rosenn B. Pre-eclampsia and gestational diabetes mellitus: does a correlation exist early in pregnancy? J Matern Fetal Neonatal Med. 2004; 15:39-43.

[24] Yogev Y, Xenakis EM, Langer O. The association between preeclampsia and the severity of gestational diabetes: the impact of glycemic control. Am J Obstet Gynecol. 2004; 191:1655-60.

[25] Zhang L, Zalewski A, Liu Y, Mazurek T, Cowan S, Martin $\mathrm{JL}$, et al. Diabetes-induced oxidative stress and low-grade inflammation in porcine coronary arteries. Circulation. 2003; 108:472-8.

The authors stated that there are no conflicts of interest regarding the publication of this article.

Received October 13, 2008. Revised April 30, 2009. Accepted May 4, 2009. Previously published online July 10, 2009. 